\title{
Sosiaalisella tuella ja kuntoutuksella merkittävä rooli rintasyövästä selviytymisessä
}

Seitsemän vuotta sitten minulla oli unelma.

Olin aiemmin saanut toimia hankesuunnittelijana ja yhtenä tutkijana Turun ammattikorkeakoulun ja Lounais-Suomen Syöpäyhdistyksen Syöpäpotilaan hyvä hoitopolku -hankkeessa. Havaitsimme tällöin eri tutkimusmenetelmin ja mittarein, että Suomessa syöpään, erityisesti rintasyöpään, sairastuneet kokevat elämänlaatunsa ja toimintakykynsä monilta osin heikentyneeksi.

Eniten minua liikutti kuitenkin tieto siitä, että syöpään sairastuneen diagnosoinnin, hoidon ja kuntoutuksen koettiin toteutuvan alueellisesti eri tavoin, vaikka terveydenhuollon rakenteet sekä hoitamisen ja kuntoutuksen perustavoitteet ja lähtökohdat ovat täysin samanlaiset.

Tarvittaisiin lisätietoa siitä, mitkä tekijät ovat yhteydessä koettuun elämänlaatuun ja elämäntyytyväisyyteen - voitaisiinko nämä selvittämällä kehittää syöpää sairastavien ja sairastaneiden hoito- ja kuntoutusmenetelmiä ja ammattilaisten osaamista ja siten ylläpitää ja parantaa kohtaamisia, kokonaisvaltaista hoitotyötä ja siihen sisältyvää potilasohjausta? Voitaisiinko tiedon pohjalta kaventaa samalla koettuja alueellisia eroja?

Vuonna 2013 laadin tutkimussuunnitelman.

15. toukokuuta väittelin.

Väitöstutkimukseni "Life satisfaction, sense of coherence and social support of Finnish breast cancer survivors - with special reference to perceived sexuality and rehabilitation" keskiössä ovat rintasyöpään sairastaneiden naisten elämäntyytyväisyys ja siihen vaikuttavat psykososiaaliset ja terveydelliset tekijät.

Tutkimukseni tavoitteena oli arvioida rintasyöpää sairastaneiden suomalaisten naisten elämäntyytyväisyyttä ja siihen vaikuttavia terveyteen liittyviä ja psykososiaalisia tekijöitä. Erityisesti tutkimustyössä tarkasteltiin sosiaalisen tuen ja seksuaalisuuden kokemusta sekä kuntoutumi- sen mahdollisuuksia syöpää sairastavien ja sen sairastaneiden keskuudessa ja kuntoutuksen merkitystä syövän sairastaneen toimintakykyyn ja selviytymiseen.

Tutkimusaihe on mielenkiintoinen ja asetelma ainutlaatuinen - vastaavaa tutkimusta ei Suomessa eikä tietääkseni maailmallakaan ole toteutettu. Vertailevalla lähestymistavalla voidaan tunnistaa tekijät, jotka ovat ominaisia tutkittavalle ryhmälle tai ilmiölle. Vertailevaa tutkimusmetodia hyödyntämällä voidaan laajentaa niin alueellista, kansallista kuin kansainvälistäkin ymmärrystä tutkittavista ilmiöistä.

Elämänlaadun ja syövästä selviytymisen tutkimuksella voidaan saavuttaa tietoa, jota voidaan hyödyntää rintasyöpää sairastavien hoidon, syöpää sairastavien hoitotyön ja potilasohjauksen sekä rintasyövän sairastaneiden kuntoutuksen kehittämistyössä.

Rintasyöpä on naisten yleisin syöpä Suomessa ja suomalaisnaisten tavallisin syöpäkuoleman syy. Rintasyöpää pidetään hyvinvoivien länsimaisten yhteiskuntien sairautena, jonka tunnettuja riskitekijöitä ovat muun muassa myöhäinen ensisynnytysikä, alhainen lasten lukumäärä ja vähäinen fyysinen aktiivisuus. Rintasyöpä-diagnoosi aiheuttaa usein muutoksia elämänlaadussa sekä fyysisessä ja psyykkisessä toimintakyvyssä.

Suomessa rintasyöpään sairastuu noin 5000 naista vuodessa. Kuolleisuus on maailman pienintä. Yhä useammat ja eri vaiheissa olevat, levinneetkin, rintasyöpätapaukset voidaan nykyään hoitaa. Syöpätapausten lisääntyessä ja kuolleisuuden laskiessa syövästä selviytyneitä naisia on yhä enemmän. Tämä edellyttää olemassa olevien tukimuotojen kehittämistä ja lisäämistä syöpähoitopolun aikana.

Kuten väitöstutkimuksessani totean, on rintasyövästä selviytyneiden kokonaisvaltaisen elä- 
mänlaadun ylläpitämiseen ja parantamiseen vaikuttavien tekijöiden tunnistaminen tärkeä kansanterveyshaaste.

Elämänlaadun käsite on moninainen. Elämänlaatua koskeva keskustelu alkoi 1960-luvulla, jolloin se ajateltiin koostuvan lähinnä objektiivisesti mitattavissa olevista ihmisen elämään liittyvistä kysymyksistä, kuten sosioekonominen tilanne, koulutustaso, asuminen ja elinympäristö. 1970luvulla elämänlaadun miellettiin koostuvan pääasiassa onnellisuudesta ja elämäntyytyväisyydestä.

Laajan nykykäsityksen mukaan kokonaisvaltainen elämänlaatu on yksilöiden ja yhteiskunnan yleistä hyvinvointia. Se sisältää tyytyväisyyden elämään, mukaan lukien fyysisen terveyden, perheen ja muut sosiaaliset yhteisöt, koulutuksen, työllisyyden, varallisuuden, turvallisuuden, vapauden, uskonnolliset vakaumukset ja ympäristön.

Elämänlaatu on erityisesti yleisen elämäntyytyväisyyden tunnetta. Sen lähikäsitteitä ovat elintaso, elinolot ja hyvinvointi, mutta elämänlaatu on rakenteeltaan abstraktimpi. Se on lähellä henkistä hyvinvointia ja heijastaa sitä, missä määrin ihminen nauttii elämästään ja onko hänellä aikaa harrastuksille ja luovuudelle, pystyykö hän tekemään haluamiaan asioita ja käyttämään kykyjään tarkoituksenmukaisesti.

Suomalainen sosiologi Erik Allardt jakaa elämänlaadun yhteisiin suhteisiin (rakastavaloving), itsensä toteuttamiseen (oleminen - being) ja elintasoon (olla - having). Allardt viittaa Maslowin tarpeiden hierarkiaan, jossa ihmisen perustarpeet on järjestetty hierarkkisesti ja vahvuuksien mukaan. Etusijalla on fysiologisten perustarpeiden tyydyttäminen.

Koherenssin tunne taas on terveyttä edistävä voimavara salutogeneesi-teoriassa, joka heijastaa yksilön selviytymiskykyä. Aaron Antonovskyn teorian mukaan yksilön terveys liittyy hänen voimavaroihinsa. Henkilöt, joiden stressin hallinnan voimavarat ovat vahvat, pystyvät tulemaan toimeen elämän erilaisten stressitekijöiden kanssa, kun taas henkilöt, joiden resurssit ovat heikentyneet, ovat alttiita stressin aiheuttamille terveyshaitoille.

Antonovskyn mukaan yksilölliset voimavarat muodostavat yhdessä koherenssin tunteen. Koherenssin tunne on "yksilön kokonaisvaltainen ja pysyvä, vaikkakin dynaaminen, varmuuden tunne siitä, että sisäinen ja ulkoinen ympäristö ovat ennustettavissa ja että asioiden sujuminen niin hyvin kuin voidaan järkevästi olettaa, on todennäköistä”.

Koherenssin tunteesta on käytetty myös nimityksiä elämänhallinta ja elämänhallintakyky. Se käsittää kolme osatekijää: ymmärrettävyys, hallittavuus ja mielekkyys.

Koherenssin tunteen on oletettu olevan melko pysyvä yksilön ominaisuus. Merkittävät elämäntilanteen muutokset voivat kuitenkin muuttaa yksilön koherenssia. Positiiviset muutokset elämäntilanteessa, kuten esimerkiksi vakavasta sairaudesta parantuminen voivat saada aikaan koherenssin vahvistumisen, kun taas negatiiviset kokemukset, kuten sairastuminen tai vakavat taloudelliset vaikeudet voivat johtaa koherenssin tunteen heikkenemiseen.

Krooniseen sairauteen sairastuminen tarkoittaa usein muutoksia elämänlaadussa, tavallisimmin sitä heikentävään suuntaan. Rintasyöpää sairastavien naisten elämänlaatua on tutkittu useissa kansallisissa ja kansainvälisissä tutkimuksissa. Rintasyövän diagnoosi ja sairauden hoidot vaikuttavat sairastuneiden elämänlaatuun sitä huonontaen. Heikentynyt kokonaisvaltainen elämänlaatu taas vaikuttaa sosiaalisiin suhteisiin ja psykologisiin tarpeisiin ja voi johtaa sairaudesta selviytymisen haasteisiin.

Syöpähoidot voivat aiheuttaa pitkäaikaisia haittavaikutuksia rintasyöpää sairastaville, millä on tutkitusti merkittävä vaikutus elämänlaatuun. Rintasyöpää sairastavat naiset kärsivät muun muassa ahdistuksesta, masennusoireista, epävarmuuden tunteesta ja psykologisesta väsymyksestä sekä uni- ja mielialahäiriöistä vielä pitkään hoitojen päätyttyä. Heikoimmaksi koetut elämänlaadun osatekijät ovat yleinen fyysinen terveys sekä psyykkinen ja hengellinen hyvinvointi.

Vaikka tiedetään, että sairastuminen vakavaan sairauteen tavallisesti heikentää elämänlaatua, useat tutkimukset raportoivat rintasyöpää sairastavien naisten elämänlaadun olevan kohtalaisen korkea, jopa korkeampi kuin terveellä naisväestöllä. Toisaalta, tutkimukset ovat osoittaneet, että rintasyöpää sairastavat naiset kokevat elämänlaatunsa heikommaksi kuin muihin syöpäsairauksiin sairastuneet. Erityisesti psykologisen ja seksuaalisen elämänlaadun osa-alueet koetaan heikoiksi.

Ikä, hoitomuodot, fyysinen aktiivisuus, terveelliset elintavat ja olemassa olevat tuen muodot, kuten sosiaalinen tuki, ovat tunnettuja elä- 
mänlaatuun vaikuttavia osatekijöitä erityisesti rintasyöpää sairastavilla naisilla. Tupakointi, vähäinen aktiivisuus ja etenkin puolisolta saatu vähäinen tai olematon sosiaalinen tuki taas heikentävät tutkitusti elämänlaatua.

Sosiaalisella tuella on merkittävä vaikutus yleiseen terveyteen ja hyvinvointiin ja sitä kautta myös elämänlaatuun. Sillä on havaittu olevan myönteisiä vaikutuksia rintasyöpää sairastavien toimintakykyyn, sairaudesta selviytymiseen ja sopeutumiseen sekä erityisesti hoitojen aikana koettuun ahdistukseen ja stressiin.

Riittämättömään tai olemattomaan sosiaaliseen tukeen liittyy syöpäkuolleisuuden merkittävä lisääntyminen. Jo 1980-luvun lopun tutkimus osoitti, että sosiaalinen eristäytyminen on samanlainen terveysriskitekijä kuin perinteisemmät korkea verenpaine, liikalihavuus ja tupakointi. Riittävä sosiaalinen tuki taas vaikuttaa positiivisesti fyysiseen, psykologiseen ja sosiaaliseen toimintakykyyn sekä parantaa seksuaalisia toimintoja. Sillä on myös myönteinen vaikutus rintasyöpää sairastavien eloonjäämislukujen kasvuun.

Rintasyöpää sairastavien naisten tärkeimmät sosiaalisen tuen lähteet ovat tutkitusti heidän perheensä: puoliso, lapset, vanhemmat ja sisarukset. Myös ystävät ja terveydenhuollon ammattilaiset sekä vapaaehtoiset mielletään tärkeiksi sosiaalisen tuen lähteiksi.

Myös kuntoutuksella on osoitettu olevan merkittävä vaikutus rintasyöpää sairastavien ja sairaudesta selvinneiden naisten yleiseen terveyteen ja selviytymiseen. Monipuolisilla ja -ammatillisilla kuntoutustoimenpiteillä on osoitettu olevan hyötyä erityisesti ylläpitämään ja parantamaan sairastuneiden hyvinvointia, osallistumista ja kokonaisvaltaista elämänlaatua. Kliiniset tutkimukset ovat osoittaneet kuntoutustoimenpiteillä olevan myönteisiä vaikutuksia syöpähoitojen aikana ja niiden jälkeen.

Kuntoutusta tarvitaan myös syövänhoidon palliatiivisessa hoidossa: pitkälle edennyttä ja parantumatonta sairautta sairastaville kuntoutuksella on todettu olevan myönteisiä vaikutuksia. Uusimpien tutkimusten mukaan varhain aloitettu kuntoutus voi vaikuttaa oirehallintaan, toimintakykyyn ja elämäntyytyväisyyteen vielä syöpähoitopolun palliatiivisessa vaiheessa.

Maailman terveysjärjestö WHO on hyväksynyt Rintasyöpäohjelman, joka kattaa sairauden ennaltaehkäisyn, varhaisen havaitsemisen, diag- noosin, hoidon ja kuntoutuksen. Kuntoutuspalvelut tulisi aloittaa mahdollisimman varhain paranemisprosessin nopeuttamiseksi, selviytymisen tukemiseksi sekä sairauden ja sen hoitojen tuomien haittojen vähentämiseksi.

15.5. tarkastettu väitöskirja koostuu neljästä osatyöstä: ensimmäisen osatyön tarkoituksena oli arvioida rintasyöpää sairastaneiden naisten itse arvioitua elämäntyytyväisyyttä ja koherenssintunnetta verenpainetautia ja masennusta sairastaviin sekä terveisiin verrokkeihin verrattuna.

Toinen osatutkimus tarkasteli rintasyöpää sairastaneiden sosiaalisen tuen saatavuutta, sosiaalisen tuen lähteitä ja koettua tuen saamisen ja antamisen välistä tasapainoa verenpainetautia ja masennusta sairastaviin sekä terveisiin verrokkeihin verrattuna.

Kolmannessa osatutkimuksessa tarkoituksena oli arvioida rintasyöpää sairastaneiden naisten tyytyväisyyttä seksielämäänsä sekä seksielämän tärkeyttä verenpainetautia ja masennusta sairastaviin sekä terveisiin verrokkeihin verrattuna.

Neljännessä osatutkimuksessa selvitettiin systemoidun kirjallisuuskatsauksen menetelmin kuntoutuksen vaikutuksia syöpää, erityisesti pitkälle edennyttä tautia, sairastavan tukimuotona.

Kaikissa kvantitatiivisissa osatöissä (I-III) käytettiin aineistona kansallista, käynnissä olevaa Health and Social Support -kohorttitutkimusdataa. Tutkimukset suoritettiin vertailevan tutkimuksen menetelmin. Osatutkimuksissa hyödynnettiin lisäksi Suomen Syöpärekisteriä ja Kansaneläkelaitoksen kansallista lääkeostotietokantaa sekä kuolinsyytilastoa.

Väitöskirjatutkimuksen tulosten perusteella voidaan todeta, että sairaudesta selviytyneet naiset ovat yhtä tyytyväisiä elämäänsä kuin terveet verrokit. He arvioivat sekä elämäntyytyväisyytensä että koherenssintunteensa merkitsevästi vahvemmaksi kuin masennuksesta kärsivät naiset. Nuoremmissa ikäryhmissä erot koherenssintunteessa rintasyöpää sairastaneiden ja terveiden kontrollien välillä olivat suurimmat. Koherenssintunteen ja elämäntyytyväisyyden välillä havaittiin positiivinen korrelaatio: mitä vahvempi koherenssitunne vastaajalla on, sitä tyytyväisempi hän on elämäänsä.

Tulokset tukevat osin aikaisempaa tutkimustietoa: vaikka tiedetään, että rintasyöpä ja syövän hoidot vaikuttavat elämänlaadun eri osa-alueisiin vuosien ajan diagnoosin ja hoitojen jälkeen, voi- 
daan nykytutkimuksen mukaan myös todeta, että rintasyövän sairastaneiden elämänlaatu, erityisesti elämäntyytyväisyys, säilyy suhteellisen hyvänä etenkin syövästä selviytymisen jälkeen.

Nämä ovat mielenkiintoisia havaintoja, sillä syöpädiagnoosin on tutkitusti todettu herättävän stressin, pelon, surun, vihan ja epävarmuuden tunteita. Tulokset voivat johtua siitä, että sairauden ja kriisin pahin vaihe on ohitettu, ja eloonjääneet ovat saaneet sairauden aikana tukipalveluita, jotka ovat saattaneet olla omiaan edistämään kokonaisvaltaista elämänlaatua käsittäen elämäntyytyväisyyden, tukemaan sairaudesta selviytymistä ja ylläpitämään toimintakykyä. Lisäksi rintasyövän hoitomuodot ovat kehittyneet vuosien saatossa, ja tällä hetkellä rintasyöpää sairastavien eloonjäämisaste on $90 \%$.

Aiempien tutkimusten mukaan rintasyöpää sairastavien naisten elämänlaatuun selkeästi vaikuttavia tekijöitä ovat psykososiaaliset tekijät, sosiodemografiset ja lääketieteelliset tekijät. Koherenssintunne, itsetunto, sosiaaliset suhteet ja tunne-elämä liittyvät rintasyövän sairastaneiden elämäntyytyväisyyteen. Hoitamaton masennus heikentää sairastuneiden yleistä elämänlaatua.

Ratkaisevimmiksi tekijöiksi rintasyöpää sairastaneiden ja sairaudesta selvinneiden naisten kokonaisvaltaisen elämänlaadun kannalta on tunnistettu seksuaalisuus ja naisellisuus. Rintasyövän, kuten monien muidenkin vakavien sairauksien, epäsuotuisat vaikutukset seksuaalisuuteen ja seksielämään ovat yleisesti tunnistettuja: erityisesti nuoret syöpäpotilaat kokevat seksuaalisuuteen liittyviä haasteita ja oman ulkonäkönsä vähemmän viehättäväksi kuin ennen sairautta.

Seksuaalinen halukkuus, seksielämän tärkeys ja tyytyväisyys seksielämään vähenevät tutkitusti rintasyöpädiagnoosin jälkeen. Nuoret rintasyöpää sairastavat ovat huolissaan seksuaalisuuden, hedelmällisyyden ja kehonkuvan muutoksista. Huomattavaa on, että seksuaalisuuteen liittyviä haasteita esiintyy vielä vuosia sairauden ja sen hoitojen jälkeen.

Tämän väitöskirjan tulosten perusteella rintasyövästä selvinneet naiset pitivät koettua seksielämäänsä melko tärkeänä, mutta olivat merkitsevästi tyytymättömämpiä seksielämäänsä kuin terveet naiset. Tämä liittyy todennäköisesti - ainakin osittain - rintasyövän hoitoihin ja hoidon jälkeisiin haasteisiin, kuten muuttuneeseen kehonkuvaan, syövän uusimisen ja kuoleman pel- koon sekä kokemukseen omasta viehättävyydestä. Kokemus henkeä uhkaavasta sairaudesta aiheuttaa myös epävarmuutta ja pelkoja ja haastaa usein naisen itsetunnon ja parisuhteen.

Rintasyöpään sairastuminen on kriisi, joka vaikuttaa kokonaisvaltaiseen elämänlaatuun ja hyvinvointiin tavallisesti niitä heikentäen. Sosiaalinen tuki ja seksuaalisuuteen liittyvät tekijät ovat tunnettuja ja merkittäviä hyvinvoinnin osatekijöitä.

Tämä väitöstyö sijoittuu monitieteelliselle tutkimuskentälle, jossa tutkitaan rintasyövästä selviytyvien naisten elämänlaatua. Syöpähoitojen nopea kehitys on luonut uudenlaisia elämäntilanteita, kun aiempaa vakavimmista sairastumisista on mahdollista selviytyä. Toisaalta syövät ovat myös lisääntyneet, joten kansanterveysongelmana syöpään sairastumisen luonne on muuttumassa, ei katoamassa.

Väitöstutkimuksen tärkeintä antia on se, miten sairastuneen selviytymistä eivät selitä pelkästään henkilökohtaiset ominaisuudet, tämän koherenssin tunne tai resilienssi eli selviytymiskyky, vaan se, mitä sairastuneelle tapahtuu sairastumisen myötä hänen sosiaalisissa suhteissaan.

Väitöstyö tuo rintasyövän tutkimuskentälle uudenlaisen ulottuvuuden erityisesti kolmesta syystä: ensiksi, väitöskirjassa tehdään vertailuja, jotka selkiyttävät ymmärrystä rintasyövän erityispiirteistä. Toiseksi, väitöstutkimuksessa tarkastellaan seksuaalisuutta, johon rintasyöpä sairautena usein vaikuttaa muuttuvan kehonkuvan kautta. Kolmanneksi, tutkimus korostaa kuntoutuksen näkökulmaa, mikä tekee sen tuloksista myös niiden soveltamisen kannalta merkittäviä.

Väitöstutkimuksen tulokset antavat aiheen hoitojen ja kuntoutumisen suunnitteluun ja rintasyöpää sairastavien ja sairastaneiden sekä heidän läheistensä monipuolisten tukimuotojen kehittämiseen, jossa psykososiaaliset tekijät tulee huomioida entistä paremmin. Erityistä huomiota tulee kiinnittää sosiaaliseen tukeen ja seksuaalisen hyvinvoinnin huomioimiseen syöpähoitopolun aikana, etenkin syöpäkuntoutuksessa.

Rintasyövästä selvinneiden kokonaisvaltaisen elämänlaadun ja toimintakyvyn parantamiseksi ja ylläpitämiseksi on tärkeää kehittää ja tarjota tukipalveluja paitsi rintasyövän sairastaneille myös heidän perheilleen ja muille läheisilleen.

Tulokset rohkaisevat terveydenhuollon ammattilaisia ottamaan puheeksi haastavat ja intii- 
mit, kokonaisvaltaiseen elämänlaatuun selkeästi vaikuttavat osatekijät syöpähoitopolun eri vaiheissa. Tutkimuksen tulosten perusteella rintasyöpään sairastuneen kumppani tai puoliso tulisi huomioida hoitopolulla entistä paremmin - potilasohjaus ja tukitoimenpiteet tulee suunnata myös sairastuneen läheisille.

Tässä väitöstutkimuksessa rintasyövän sairastaneiden ja siitä selviytyneiden naisten elämänlaatua ja siihen vaikuttavia tekijöitä pyrittiin arvioimaan monipuolisesti, kansalliseen kohorttitutkimukseen, siinä käytettyihin, tunnustettuihin ja valideihin mittareihin sekä kirjallisuuskatsaukseen perustuen.

Tutkimuksen avulla saatiin uutta tietoa rintasyövän sairastaneiden suomalaisnaisten kokonaisvaltaisesta elämänlaadusta, mikä edesauttaa olemassa olevien tukimuotojen kehittämistä.

Terveyden edistäminen ja sairauksien ehkäisy ovat Suomen terveyspolitiikan ensisijaisia tavoitteita. Syöpä on osa ei-tarttuvien kansantautien ryhmää, johon luetaan syövän lisäksi sydän- ja verisuonisairaudet, diabetes ja krooniset keuhkosairaudet.

Kansallisessa syöpäsuunnitelmassa todetaan, että syövän hoito varhaisessa vaiheessa säästää sekä sairastuneen ja hänen läheistensä voimavaroja että yhteiskunnallisia ja taloudellisia resursseja. Kuntoutus ja kuntoutumisen tuki kuuluvat olennaisena osana syöpäpotilaan hyvään hoitoon koko hoitopolun ajan. Kuntoutumisen tuen tulee olla yksilölliset tarpeet huomioivaa.

Hyvin suunniteltujen ja järjestettyjen, yhteneväisten palvelujen avulla voidaan hyvinvointivaikutusten lisäksi parantaa elämänlaatua sekä lisätä kansalaisten tasa-arvoa.

Master of Health Care Minna Salakari esitti väitöskirjansa "Life satisfaction, sense of coherence and social support of Finnish breast cancer survivors - with special reference to perceived sexuality and rehabilitation" julkisesti tarkastettavaksi Turun yliopistossa perjantaina 15.5.2020.

Vastaväittäjänä toimi emerita professori AnnaMaija Pietilä Itä-Suomen yliopistosta ja kustoksena professori Sakari Suominen Turun yliopistosta. Tilaisuus oli suomenkielinen. Väitöksen alana oli kansanterveystiede.

\section{Minna SALAKari}

Arndt V, Stegmaier C, Ziegler H, Brenner H. A population-based study of the impact of specific symptoms on quality of life in women with breast cancer 1 year after diagnosis. Cancer. 2006;107(10):2496-2503.

Arora NK, Finney Rutten LJ, Gustafson DH, Moser R, Hawkins RP. Perceived helpfulness and impact of social support provided by family, friends, and health care providers to women newly diagnosed with breast cancer. Psychooncology. 2007;16(5):474-486.

Arving C, Sjödén PO, Bergh J, et al. Satisfaction, utilisation and perceived benefit of individual psychosocial support for breast cancer patients - A randomised study of nurse versus psychologist interventions. Patient Educa Couns. 2006;62(2):235243.

Atlantis E, Sullivan T. Bidirectional association between depression and sexual dysfunction: a systematic review and meta-analysis. J Sex Med. 2012;9(6):1497-1507.

Avis NE, Crawford S, Manuel J. Quality of life among younger women with breast cancer. J Clin Oncol. $2005 ; 23(15): 3322-3330$.
Antonucci TC. Measuring social support networks: Hierarchical mapping technique. Generations. 1986;3:10-12. 
Baker F, Denniston M, Smith T, West M. Adult cancer survivors: How are they faring? Cancer. 2005;104(11 Suppl): 2565-2576.

Balducci L, Fossa SD. Rehabilitation of older cancer patients. Acta Oncol. 2013;52(2):233-2388.

Bartula I, Sherman KA. Screening for sexual dysfunction in women diagnosed with breast cancer: systematic review and recommendations. Breast Cancer Res Treat. 2013;141(2):173-185.

Battaglini CL, Mills RC, Phillips BL, Lee JT, Story CE, Nascimento MG, Hackney AC. Twenty-five years of Beckjord E, Campas BE. Sexual quality of life in women with newly diagnosed breast cancer. J Psychosoc Oncol. 2007;25(2):19-36.

Begovic-Juhant A, Chmielewski A, Iwuagwu S, Chapman LA. Impact of body image on depression and quality of life among women with breast cancer. J Psychosoc Oncol. 2012;30(4):446-460.

Ben Charif A, Bouhnik AD, Rey D, et al. Satisfaction with fertility- and sexuality-related information in young women with breast cancer--ELIPPSE40 cohort. BMC Cancer. 2015;15:572.

Bergh H, Baigi A, Fridlund B, Marklund B. Life events, social support and sense of coherence among frequent attenders in primary health care. Public Health. 2006;120(3):229-236. World J Clin Oncol. 2014; 10; $5(2): 177-90$.

Beutell, N. J. Life satisfaction (in relation to workfamily variables). Sloan Work-Family Encyclopedia (Boston College), 2006.

Bloom JR, Stewart SL, Chang S, Banks PJ. Then and now: quality of life of young breast cancer survivors. Psychooncology. 2004;13(3):147-160.

Bloom JR, Stewart SL, Johnston M, Banks P, Fobair P. Sources of social support and the physical and mental well-being of young women with breast cancer. Soc Sci Med. 2001;53(11):1513-1524.

Boquiren VM, Esplen MJ, Wong J, Toner B, Warner E, Malik N. Sexual functioning in breast cancer survivors experiencing body image disturbance. Psychooncology. 2016;25(1):66-76

Burgess C, Cornelius V, Love S, Graham J, Richards M, Ramirez A. Depression and anxiety in women with early breast cancer: five year observational cohort study. BMJ. 2005;330(7493):702.

Carlson LE, Ottenbreit N, St Pierre M, Bultz BD. Partner understanding of the breast and prostate cancer experience. Cancer Nurs. 2001;24(3):231-239.

Carver CS, Smith RG, Petronis VM, Antoni MH. Quality of life among long-term survivors of breast cancer: Different types of antecedents predict different classes of outcomes. Psychooncology. 2006;15(9):749_ 758

Chu WO, Dialla PO, Roignot P, Bone-Lepinoy MC, Poillot M, Coutant C, Arveux P, Dabakuyo-Yonli TS6,7,8. Determinants of quality of life among long-term breast cancer survivors. Qual Life Res. 2016;25(8):1981-90.

doi: 10.1007/s11136-016-1248-z.
Cimprich B, Ronis DL, Martinez-Ramos G. Age at diagnosis and quality of life in breast cancer survivors. Cancer Pract. 2002;10(2):85-93.

de Morais FD, Freitas-Junior R, Rahal RM, Gonzaga CM. Sociodemographic and clinical factors affecting body image, sexual function and sexual satisfaction in women with breast cancer. J Clin Nurs 2016;25:155765 .

Dittus KL, Gramling RE, Ades PA. Exercise interventions for individuals with advanced cancer: A systematic review. Prev Med. 2017;104:124-132.

Ell K. Social networks, social support and coping with serious illness: The family connection. Soc Sci Med. 1996;42(2):173-183.

Engel J, Kerr J, Schlesinger-Raab A, Eckel R, Sauer H, Hölzel D. Comparison of breast and rectal cancer patients' quality of life: results of a fouryear prospective study. Eur J Cancer Care (Engl). 2003b;12(3):215-223.

Engel J, Kerr J, Schlesinger-Raab A, Eckel R, Sauer H, Hölzel D. Comparison of breast and rectal cancer patients' quality of life: results of a fouryear prospective study. Eur J Cancer Care (Engl). 2003b;12(3):215-223.

Eriksson M, Lindström B. Antonovsky's sense of coherence scale and its relation with quality of life: a systematic review. J Epidemiol Community Health. 2007;61(11):938-944.

Eva G, Wee B. Rehabilitation in end-of-life management. Curr Opin Support Palliat Care. 2010;4(3):158-162.

Finnish Breast Cancer Group (FBCG). Rintasyövän valtakunnallinen diagnostiikka- ja hoitosuositus. 2016.

Finnish Breast Cancer Group (FBCG). The treatment of breast cancer. 2015 .

Finnish Cancer Registry. Cancer Statistics, 2016. Available: https://cancerregistry.fi/statistics/cancerstatistics/ Accessed November 3, 2018.

Finnish Cancer Registry. Cancer Statistics, 2019. Available: https://cancerregistry.fi/statistics/cancerstatistics/ Accessed May 3, 2019.

Fobair P, Spiegel D. Concerns about sexuality after breast cancer. Cancer J. 2009;15(1):19-26.

Fobair P, Stewart SL, Chang S, D’Onofrio C, Banks PJ, Bloom JR. Body image and sexual problems in young women with breast cancer. Psychooncology. 2006;15:579-594.

Gilbert E, Ussher JM, Perz J. Sexuality after breast cancer: A review. Maturitas. 2010;66(4):397-407.

International Agency for Research on Cancer (IARC). GLOBOCAN 2018 - Global Cancer Data.

Hautamäki-Lamminen K. Seksuaalisuuden muutokset syöpään sairastuessa. Tiedontarpeet ja tiedonsaanti. Akateeminen väitöskirja. Academic dissertation in Finnish. 2012.

Heikkinen S, Miettinen J, Pukkala E, Koskenvuo M, Malila N, Pitkäniemi J. Impact of major life events on breast-cancer-specific mortality: A case fatality study 
on 8000 breast cancer patients. Cancer Epidemiol. 2017;48:62-69.

House JS, Landis KR, Umberson D.

Social relationships and health. Science. 1988;241(4865):540-545.

House JS. Work stress and social support. Reading, MA: Addison-Wesley; 1981.

Kenne Sarenmalm E, Browall M, Persson LO, FallDickson J, Gaston-Johansson F. Relationship of sense of coherence to stressful events, coping strategies, health status, and quality of life in women with breast cancer. Psychooncology. 2011;22(1):20-27.

Lindblad C, Langius-Eklöf A, Petersson LM, Sackey H, Bottai M, Sandelin K. Sense of coherence is a predictor of survival: A prospective study in women treated for breast cancer. Psychooncology. 2018;27(6):1615-1621.

Male DA, Fergus KD, Cullen K. Sexual identity after breast cancer: sexuality, body image, and relationship repercussions. Curr Opin Support Palliat Care. 2016;10(1):66-74.

Manne S, Ostroff J, Winkel G, Goldstein L, Fox K, Grana G. Posttraumatic growth after breast cancer: patient, partner, and couple perspectives. Psychosom Med. 2004;66(3):442-454.

Nurminen R, Salakari M, Lämsä P, Kemppainen T. Syöpäsairaiden ja heidän läheistensä kuntoutuksen tuloksellisuus. In Nurminen R, Ojala K, eds. Tuloksellisuus syöpäsairaiden kuntoutuksessa. Turku, Finland: Juvenes Print; 2001:82-101.
Oldervoll LM, Loge JH, Lydersen S, et al. Physical exercise for cancer patients with advanced disease: a randomized controlled trial. Oncologist 2011;16(11):1649-1657.

Salonen P, Rantanen A, Kellokumpu-Lehtinen PL, Huhtala H, Kaunonen M. The quality of life and social support in significant others of patients with breast cancer--a longitudinal study. Eur J Cancer Care (Engl). 2014;23(2):274-283.

Sarason IG, Levine HM., Basham RB, Sarason BR. Assessing social support: The Social Support Questionnaire. J Pers Soc Psychol. 1983;44(1):127139.

Silver JK. Rehabilitation in women with breast cancer. Phys Med Rehabil Clin N Am. 2007;18(3):521-37.

Silver JK, Baima J, Mayer RS. Impairment-driven cancer rehabilitation: an essential component of quality care and survivorship. CA Cancer J Clin. 2013;63(5): 295-317.

Suominen S, Helenius H, Blomberg H, Uutela A, Koskenvuo M. Sense of coherence as a predictor of the subjective state of health. Results of a 4 years of follow-up of adults. J Psychosom Res. 2001:50(2):7786.

Youlden DR, Cramb SM, Dunn NA, Muller JM, Pyke $\mathrm{CM}$, Baade PD. The descriptive epidemiology of female breast cancer: an international comparison of screening, incidence, survival and mortality. Cancer Epidemiol. 2012;36(3):237-248. 